\title{
Experimental and FEA analysis of Composite Leaf Spring for Natural Frequency by changing Fiber orientation
}

\author{
D.S.Hasbe ${ }^{1}$, M.C.Swami ${ }^{2}$ \\ ${ }^{1}$ Mechanical Department, M. S. Bidve Engineering College, Latur, Maharashtra, India \\ ${ }^{2}$ Assistant professor, Mechanical Department, M. S. Bidve Engineering College, Latur, Maharashtra, India
}

\begin{abstract}
The work is carried out on composite leaf spring of a commercial vehicle. The purpose of this work is to carryout design and analysis of composite leaf spring with experimental design consideration and loading condition. The material of leaf spring is E-GFRC (Glass Fiber reinforced composite). The GFRC leaf springs are manufactured by hand lay-up method which were evaluated and study. The model of composite leaf spring is prepared and analyzed using ANSYS16.2 for the modal analysis under defined loading condition. The experimental and FEA result compared for validation.

Key Words: Composite Mono Leaf Spring, Vibration Analysis, FEA, FFT Analyzer.
\end{abstract}

\section{Introduction}

Vibration is the motion of a particle or a body or system of connected bodies displaced from a position of equilibrium. Most vibrations are undesirable in machines and structures because they produce increased stresses, energy losses, causes added wear, increase bearing loads, induce fatigue, create passenger discomfort in vehicles, and absorb energy from the system. Rotating machine parts need careful balancing in order to prevent damage from vibrations. Vibration occurs when a system is displaced from a position of stable equilibrium. The system tends to return to this equilibrium position under the action of restoring forces (such as the elastic forces, as for a mass attached to a spring, or gravitational forces, as for a simple pendulum). The system keeps moving back and forth across its position of equilibrium. A system is a combination of elements intended to act together to accomplish an objective. For example, an automobile is a system whose elements are the wheels, suspension, car body, and so forth. A static element is one whose output at any given time depends only on the input at that time while a dynamic element is one whose present output depends on past inputs. In the same way we also speak of static and dynamic systems. A static system contains all elements while a dynamic system contains at least one dynamic element. [1]

A physical system undergoing a time-varying interchange or dissipation of energy among or within its elementary storage or dissipative devices is said to be in a dynamic state. All of the elements in general are called passive, i.e., they are incapable of generating net energy. A dynamic system composed of a finite number of storage elements is said to be lumped or discrete, while a system containing elements, which are dense in physical space, is called continuous. [1]

\subsection{Material}

\section{Methodology}

The material used for leaf springs is usually a plain carbon steel having 0.90 to $1.0 \%$ carbon. The leaves are heat treated after the forming process. The heat treatment of spring steel products greater strength and therefore greater load capacity, greater range of deflection and better fatigue properties. [8]

A. Carbon Fibers: Their advantages include high specific strength and modulus, low coefficient of thermal expansion and high fatigue strength. Graphite, when used alone has low impact resistance. Its drawbacks include high cost, low impact resistance and high electrical conductivity. [8]

B. Glass Fibers: The main advantage of Glass fiber over others is its low cost. It has high strength, high chemical resistance and good insulating properties. The disadvantages are low elastic modulus poor adhesion to polymers, low fatigue strength and high density, which increase leaf spring weight and size. Also crack detection becomes difficult. [8]

\subsection{Selection of Fiber}

Table-1. Properties of fiber

\begin{tabular}{|l|l|l|}
\hline Sr.No. & Type of Fiber & Properties \\
\hline 1 & Glass Fiber & - \\
\hline a) & E-glass & High Stiffness, high buckling, weak in shear, low cost. \\
\hline b) & S-glass & High Stiffness, high buckling, weak in shear, high cost. \\
\hline 2 & Carbon fiber & High strength, high modulus, low density, high temperature resistance, considerably high cost. \\
\hline 3 & Ceramic & High temperature resistance, low thermal conductivity. \\
\hline
\end{tabular}


Experimental and FEA analysis of Composite Leaf Spring for Natural Frequency by changing Fiber ..

From the above table we have selected the E-glass fiber and resin epoxy for fabrication of composite leaf spring.

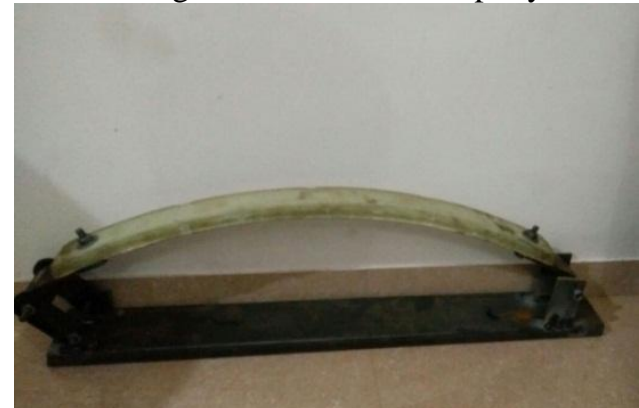

Fig. 1- Fabricated composite Leaf Spring

\section{3. Result And Discussion}

3.1 Finite Element Analysis (FEA)

FEA analysis is done by changing the fiber orientation.

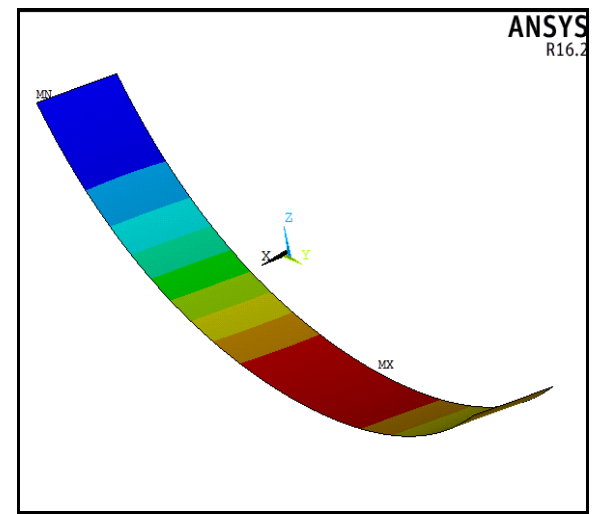

Fig.2. First mode shape of 0-90 configuration @ $31.05 \mathrm{~Hz}$

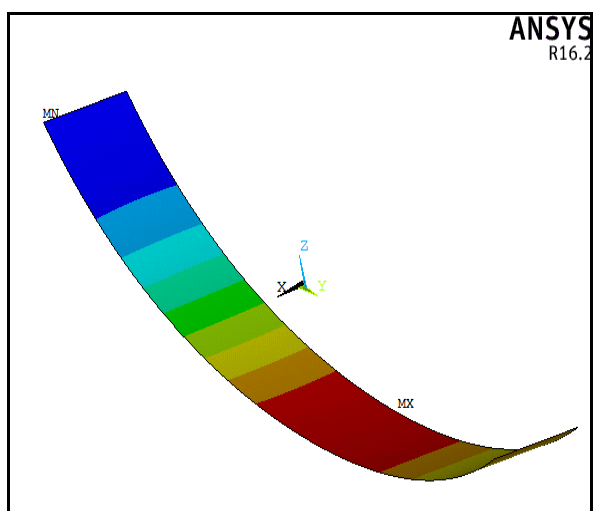

Fig.3. First mode shape of 0- 45 configurations @ $29.18 \mathrm{~Hz}$

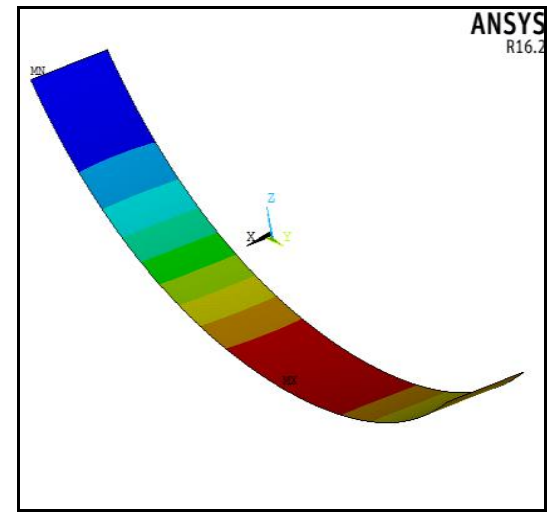

Fig.4. First mode shape of 45 - 45 configuration @ $25.41 \mathrm{~Hz}$ 


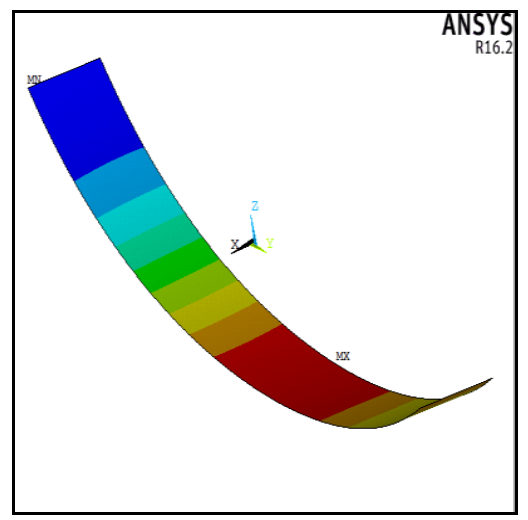

Fig.5. First mode shape of 30-60 configuration @ 26.27Hz

Table 2: Results of Natural Frequency of Glass Fiber Epoxy Composite Leaf Spring.

\begin{tabular}{|l|l|}
\hline Fibre Orientation & Natural Frequency of First Mode in $\mathrm{Hz}$ \\
\hline $0-90$ & 31.05 \\
\hline $0-45$ & 29.18 \\
\hline $45-45$ & 25.41 \\
\hline $30-60$ & 26.72 \\
\hline
\end{tabular}

\subsection{Experimental Analysis}

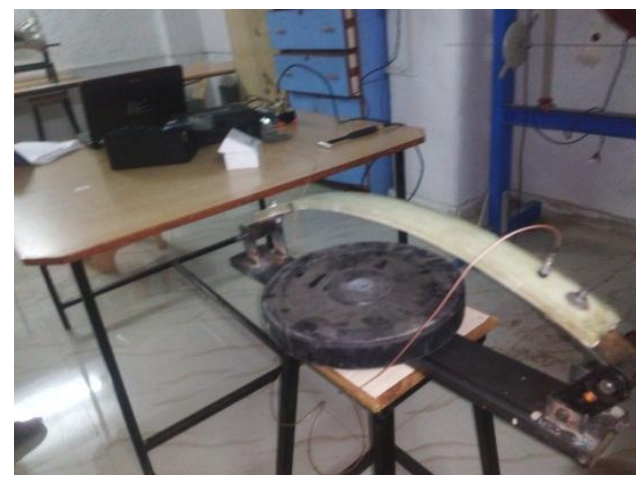

Fig. 6. Experimental setup

Experimental analysis of the leaf spring is done on FFT analyzer.

Experimental Results of average Natural Frequency of Glass Fiber Epoxy Composite Leaf Spring is $28.17 \mathrm{~Hz}$.

\section{Conclusion}

1. Composite leaf spring has greater vibration absorbing capacity than conventional leaf spring

2. The natural frequency is higher for 0-90 fiber orientation and minimum for 45-45 fiber orientation.

\section{Acknowledgement}

I would like to thank Prof.M.C.Swami for motivating me to undertake the project to study the vibrational analysis of leaf springs. I would also like to thank, Prof.S.G.Mantri, Prof.P.S.Patil, providing me the Technical Knowledge about this project.

\section{References}

[1]. Mohansing R. Pardeshi, Dr. (Prof.) P. K. Sharma, Prof. Amit Singh, Vibration Analysis of E-Glass Fiber Resin Mono Leaf Spring Used In Lmv, International Journal of Advanced Technology in Engineering and Science, Volume No.02, Issue No. 05, May 2014,pp.305-311.

[2]. Pramod K Shinde,Piyush R Talekar,Y.Y.Kamble,Sandip Desai, "Vibration analysis of composite leaf spring used for passenger car", International Journal, Innovative Research in Science and Engineering, Vol.No.2,Issue 03,March 2016, pp. 676-683.

[3]. Prof.N.D.Patil,Prof.P.P.Awate,Prof.N.V.Hargude, “Analysis of Carbon Fiber Epoxy Composite Leaf Springs", International Journal for Scientific Research and Development, Vol.No.2,Issue 12, 2015, pp. 355-357.

[4]. Sagar B Mahajan, M.C.Swami, Parmeshwar Patil, "Experimental and FEA Analysis of composite leaf spring by varying thickness," International Journal of Research in Engineering and Technology, Vol.No.4,Issue 01,January 2015, pp. 79-87.

[5]. N.Anu Radha, C.Sailaja , S.Prasad Kumar, U.Chandra Shekar Reddy \& Dr. A.Siva Kumar, "Stress Analysis And Material Optimization Of Master Leaf Spring", International Journal of Application or Innovation in Engineering \& Management, Volume 2, Issue 10, October 2013,pp.324-329. 
[6]. Sorathiya Mehul,Dhaval B. Shah, Vipul Bhojawala,“ Analysis Of Composite Leaf Spring Using FEA For Light Vehicle Mini Truck”, Journal Of Information, Knowledge And Research In Mechanical Engineering, Volume - 02, Issue - 02,pp. 424-428.

[7]. Ghodake A. P., Patil K.N., "Analysis of Steel and Composite Leaf Spring for Vehicle", IOSR Journal of Mechanical and Civil Engineering, Volume 5, Issue 4 (Jan. - Feb. 2013), pp. 68-76

[8]. Prof. N.D.Patil1 Prof. P.P. Awate2 Prof. N.V. Hargude, Analysis of Carbon Fiber Epoxy Composite Leaf Springs, International Journal for Scientific Research \& Development,Vol.2,Issue 12, 2015,pp.355-357 